\title{
Effect of rubbing force magnitude on bond strength of universal adhesives applied in self-etch mode
}

\author{
Özgür IRMAK¹, Batu Can YAMAN¹, Ekim Onur ORHAN², Fusun OZER ${ }^{3}$ and Markus B. BLATZ ${ }^{3}$ \\ ${ }^{1}$ Department of Restorative Dentistry, Faculty of Dentistry, Eskisehir Osmangazi University, Meselik Yerleskesi, 26480 Eskisehir, Turkey \\ ${ }^{2}$ Department of Endodontics, Faculty of Dentistry, Eskisehir Osmangazi University, Meşelik Yerleskesi, 26480 Eskisehir, Turkey \\ ${ }^{3}$ Department of Preventive and Restorative Sciences, School of Dental Medicine, University of Pennsylvania, 240 South 40 th Street, Philadelphia, \\ PA 19104, USA \\ Corresponding author, Özgür IRMAK; E-mail: zgrrmk@gmail.com
}

\begin{abstract}
This study investigated the effect of rubbing force magnitude on dentin bond strengths of multi-mode adhesives applied in self-etch mode. Seventy-two extracted human molar teeth were used. Two different universal adhesives Single Bond Universal (SB) and Clearfil Universal (CL) were applied onto dentin surfaces in three different modes: without rubbing (NR), rubbing with 40 gf (gramforce) (40) or $80 \mathrm{gf}$ (80) load. Teeth were restored with a resin composite. Half of the specimens were subject to thermal aging (10,000 cycles). Microtensile bond strength was measured and data were statistically analyzed with two-way analysis of variance and Tukey's test $(\alpha=0.05)$. Baseline bond strength values for CL adhesive were improved by rubbing (40 and 80 gf) as compared to no rubbing $(p<0.05)$. Rubbing did not significantly improve bond strength values for SB, regardless of aging $(p>0.05)$. Rubbing improves bonding performance of some universal adhesives to dentin when applied in self-etch mode.
\end{abstract}

Keywords: Adhesion, Universal adhesive, Rubbing, Self-etch

\section{INTRODUCTION}

Current trends in dental adhesive technology follow a philosophy to simplify the application process to save time and, by eliminating multiple steps, reduce the possibility of error. This simplification commenced with total-etch (TE) systems ${ }^{1)}$. Originally, three-step $\mathrm{TE}$ adhesives required separate application steps of phosphoric acid, primer, and adhesive. Simplified versions are two-step TE systems, which combine the primer and adhesive in single bottle. Subsequently, self-etch (SE) systems were introduced, eliminating the application of phosphoric acid and rinsing. Instead, they combined acid with primer application, without the necessity of rinsing ${ }^{2)}$. In two-step SE systems, the acidic primer and adhesive are applied in separate steps. A simplified version of those are the one-step SE systems, which combine acidic primers and adhesives into single bottle, also called all-in-one systems.

Recently, a new family of adhesive systems named as universal adhesives were introduced. Universal adhesives are based on the all-in-one concept of SE adhesives and can be used in three different modes; TE, $\mathrm{SE}$, and selective-etch ${ }^{3}$. They also can provide adhesion to multiple substrates other than tooth surfaces, including resin composites, metals, zirconia, and silicabased ceramics ${ }^{4}$.

The rationale of reducing the number of application steps is to limit potential errors by the clinician, thus decreasing technique sensitivity. However, some research indicates that simplification of $\mathrm{TE}$ and $\mathrm{SE}$ adhesives results in decreased clinical performance ${ }^{5}$. In an attempt to improve the quality of adhesive-resin interface of simplified adhesives (2-step TE, 1-step SE), some authors suggest specific clinical procedures such as rubbing action, application of multiple adhesive coats, delayed light curing, additional layer of hydrophobic resin coating, prolonging the exposure time during light curing, warm air-stream for solvent evaporation, and use of an electrically assisted device ${ }^{6}$. One of these approaches, rubbing the adhesive onto tooth surfaces more forcefully, is simple to perform and does not require any additional step or equipment. It is known that rubbing action decreases the degradation rate of the hybrid layer by increasing the penetration of resin monomers into the collagen fibrils ${ }^{6}$. It also increases the resin-dentin bond strength by improving the solvent evaporation, thus, increasing the clinical performance of SE and TE adhesives ${ }^{6}$. In the literature, effects of rubbing the adhesives with micro-brushes on dentin bond strength of both TE and SE adhesives have been well documented by laboratory studies ${ }^{7-15}$ and a single clinical trial ${ }^{16)}$ (Table 1). Rubbing action investigated in these studies were referred to in multiple terms, such as "vigorous rubbing", "slight rubbing", "rigorous agitation", "vigorous agitation", "active application". Although rubbing action was found to improve dentin bond strengths, some of these studies did not mention or define the magnitude of force applied during the adhesive procedures. Most recently, many manufacturers of adhesive systems have started to recommend rubbing of their adhesives onto tooth surfaces. Unfortunately, there is no information about the effect of rubbing force on dentin surfaces with universal adhesive systems in the literature. Additionally, the magnitude of force to be applied during rubbing action has not been studied yet.

This study investigated the effect of rubbing force magnitude on dentin bond strengths of multi-mode 
Table 1 Studies about the effect of rubbing action

\begin{tabular}{|c|c|c|c|c|}
\hline$\#$ & Reference & $\begin{array}{l}\text { Adhesive } \\
\text { system }\end{array}$ & Rubbing action & Outcome \\
\hline 1 & $\begin{array}{l}\text { Miyazaki et al., } \\
1996^{10)}\end{array}$ & 3 -step TE & $\begin{array}{l}\text { Active } \\
\text { Inactive }\end{array}$ & No significant differences \\
\hline 2 & $\begin{array}{l}\text { Jacobsen and } \\
\text { Söderholm, 1998 }\end{array}$ & 3 -step TE & $\begin{array}{l}\text { With agitation } \\
\text { Without agitation }\end{array}$ & $\begin{array}{l}\text { Bond strength increased for water-based } \\
\text { primer, decreased for acetone-based } \\
\text { primer with agitation }\end{array}$ \\
\hline 3 & Chan et al., 2003 ${ }^{15)}$ & $\begin{array}{l}2 \text {-step SE } \\
1 \text {-step SE }\end{array}$ & $\begin{array}{l}\text { Passive } \\
\text { Agitation }\end{array}$ & Agitation more effective \\
\hline 4 & $\begin{array}{l}\text { Dal-Bianco et al., } \\
2006^{11}\end{array}$ & 2 -step TE & $\begin{array}{l}\text { No rubbing } \\
\text { Slight rubbing }(4.0 \pm 1.0 \mathrm{~g}) \\
\text { Vigorous rubbing }(34.5 \pm 6.9 \mathrm{~g})\end{array}$ & $\begin{array}{l}\text { On dry dentin, vigorous rubbing } \\
\text { effective, on wet dentin, light rubbing is } \\
\text { enough }\end{array}$ \\
\hline 5 & $\begin{array}{l}\text { Velasquez et al., } \\
2006^{19)}\end{array}$ & 2 -step SE & $\begin{array}{l}\text { Passive } \\
\text { Agitation }\end{array}$ & $\begin{array}{l}\text { Agitation more effective for some } \\
\text { adhesives }\end{array}$ \\
\hline 6 & Reis et al., $2007^{13)}$ & 2 -step TE & $\begin{array}{l}\text { No rubbing } \\
\text { Slight rubbing }(4.0 \pm 1.0 \mathrm{~g}) \\
\text { Vigorous rubbing }(34.5 \pm 6.9 \mathrm{~g})\end{array}$ & $\begin{array}{l}\text { Vigorous rubbing more effective than } \\
\text { slight rubbing and no rubbing }\end{array}$ \\
\hline 7 & $\begin{array}{l}\text { do Amaral et al. } \\
\text { 20098) }\end{array}$ & 1-step SE & $\begin{array}{l}\text { Inactive application } \\
\text { Active mode }(34.5 \pm 6.9 \mathrm{~g})\end{array}$ & Active application more effective \\
\hline 8 & $\begin{array}{l}\text { Tewari and Goel, } \\
2009^{14)}\end{array}$ & 2 -step SE & $\begin{array}{l}\text { No rubbing } \\
\text { Vigorous rubbing }\end{array}$ & $\begin{array}{l}\text { Agitation effective when air-drying } \\
\text { primer for } 5 \mathrm{~s} \text {; no effect of agitation } \\
\text { when primer was dried for } 0 \mathrm{~s} \text { or } 10 \mathrm{~s}\end{array}$ \\
\hline 9 & $\begin{array}{l}\text { do Amaral et al., } \\
2010^{9)}\end{array}$ & 1-step SE & $\begin{array}{l}\text { Passive } \\
\text { Agitation }(34.5 \pm 6.9 \mathrm{~g})\end{array}$ & Agitation more effective \\
\hline 10 & $\begin{array}{l}\text { Loguercio et al., } \\
2011^{16)}\end{array}$ & 2 -step TE & $\begin{array}{l}\text { No rubbing } \\
\text { Slight rubbing }(4.0 \pm 1.0 \mathrm{~g}) \\
\text { Vigorous rubbing }(34.5 \pm 6.9 \mathrm{~g})\end{array}$ & Vigorous rubbing more effective \\
\hline 11 & $\begin{array}{l}\text { Loguercio et al., } \\
2011^{7)}\end{array}$ & 1-step SE & $\begin{array}{l}\text { Inactive } \\
\text { Active }(34.5 \pm 6.9 \mathrm{~g})\end{array}$ & Active application more effective \\
\hline
\end{tabular}

adhesives applied in a self-etch manner. The null hypothesis tested was that different adhesive rubbing forces would not influence micro-tensile bond strength ( $\mu$ TBS) of universal adhesives to dentin surfaces.

\section{MATERIALS AND METHODS}

\section{Tooth selection and preparation}

Seventy-two extracted sound human third molars with similar crown heights were selected and stored for less than 1 month in $0.5 \%$ chloramine-T solution. Teeth were embedded in epoxy resin (Epofix, Struers, Cleveland, $\mathrm{OH}, \mathrm{USA}$ ). A model trimmer was used to grind away only occlusal enamel, exposing a flat superficial dentin surface (Fig. 1). This superficial dentin was used as a reference plane for further preparation. Deeper coronal dentin surface was obtained by cutting $2 \mathrm{~mm}$ below the reference plane using a low speed saw (Isomet 1000, Buehler, Lake Bluff, IL, USA) under running water. The absence of pulp tissue exposure on the dentine surfaces was verified under a stereomicroscope (SV 6, Zeiss, Oberkochen, Germany). Each dentin surface was then polished under running water with 600-grit silicon carbide ( $\mathrm{SiC}$ ) paper for $30 \mathrm{~s}$ to create a standardized smear layer covered dentin surface.

\section{Experimental groups}

The polished specimens were randomly assigned to two main groups with respect to the adhesive used. Each main group was divided into three subgroups according the application mode. Universal adhesives (Table 2) were applied onto dentin surfaces as follows (Fig. 2):

- SB-NR: Single Bond Universal (SB; 3M ESPE, St Paul, MN, USA) adhesive was spread onto dentin surface without any deliberate pressure for $2 \mathrm{~s}$, and left undisturbed for $18 \mathrm{~s}$.

- SB-40: SB was rubbed onto dentin surface for 20 $\mathrm{s}$ with a maximum load of $40 \mathrm{gf}$.

- SB-80: SB was rubbed onto dentin surface for 20 $\mathrm{s}$ with a maximum load of $80 \mathrm{gf}$. 


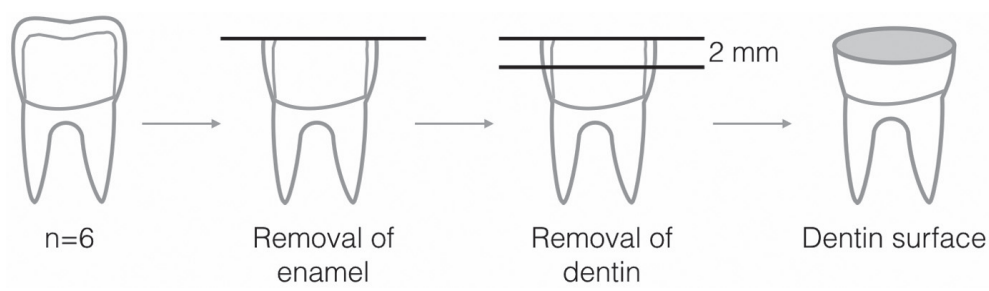

Fig. 1 Dentin specimen preparation.

Table 2 Composition of the universal adhesives tested

\begin{tabular}{lcl}
\hline \multicolumn{1}{c}{ Universal adhesive } & $\mathrm{pH}$ & \multicolumn{1}{c}{ Composition* } \\
\hline $\begin{array}{l}\text { SingleBond Universal (SB) } \\
\text { (3M ESPE, St. Paul, MN, USA) }\end{array}$ & 2.7 & $\begin{array}{l}\text { 10-MDP phosphate monomer, Vitrebond copolymer, HEMA, } \\
\text { dimethacrylate resins, filler, silane, initiators, ethanol, water }\end{array}$ \\
$\begin{array}{l}\text { Clearfil Universal Bond (CL) } \\
\text { (Kuraray Noritake Dental, Tokyo, Japan) }\end{array}$ & 2.3 & $\begin{array}{l}\text { 10-MDP, hydrophilic aliphatic dimethacrylate, HEMA, BIS-GMA, } \\
\text { colloidal silica, silane, accelerators, initiators, ethanol, water }\end{array}$ \\
\hline
\end{tabular}

*HEMA: 2-hydroxyethyl methacrylate; BIS-GMA: Bisphenol-A-glycidyl methacrylate; MDP: 10-Methacryloyloxydecyl dihydrogen phosphate

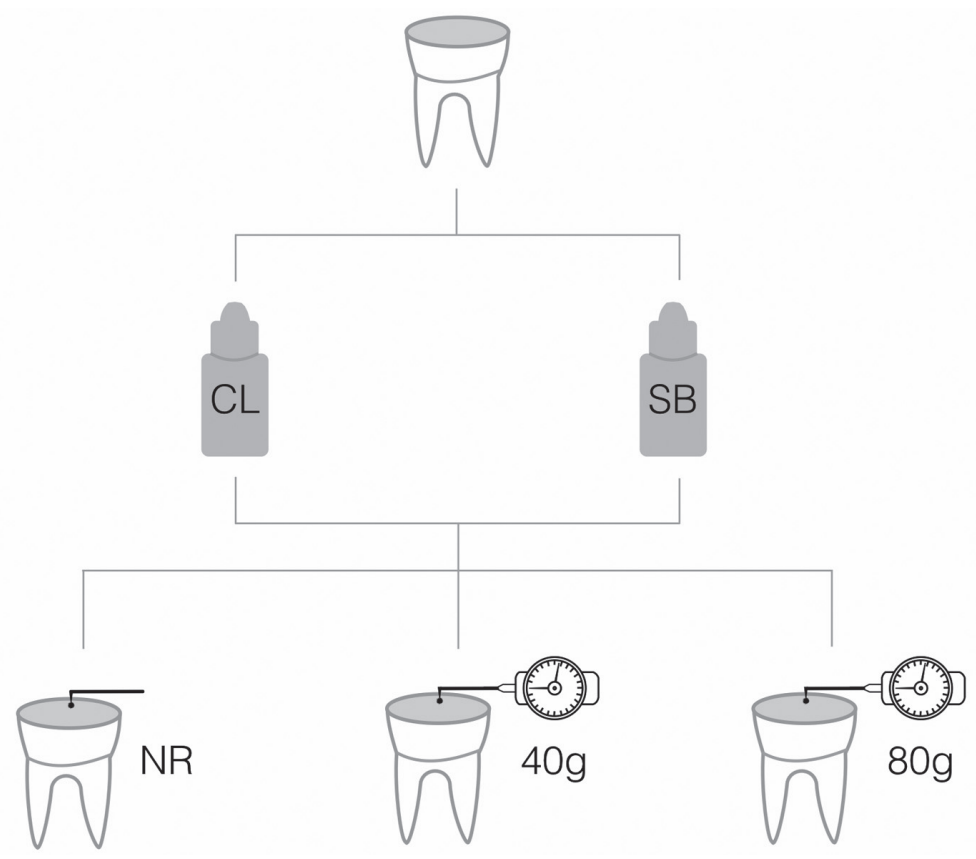

Fig. 2 Experimental design of the study.

CL: Clearfil universal bond; SB: Single bond universal; NR: No-rubbing

- CL-NR: Clearfil Universal (CL; Kuraray Noritake Dental, Tokyo, Japan) adhesive was spread onto dentin surface without any deliberate pressure for $2 \mathrm{~s}$ and left undisturbed for $8 \mathrm{~s}$.

- CL-40: CL was rubbed onto dentin surface for $10 \mathrm{~s}$ with a maximum load of $40 \mathrm{gf}$.

- CL-80: CL was rubbed onto dentin surface for $10 \mathrm{~s}$ with a maximum load of $80 \mathrm{gf}$.

\section{Rubbing application}

A rigid micro-brush (Micro Tim Application Brushes, Voco, Cuxhaven, Germany) attached to a brush holder (Brush holder, Voco) was fixed at right angle to the feeler tip of a force gauge (Correx Tension Gauge, Haag- 
Streit, Koeniz, Switzerland). Manual force was applied to dentin surface until the brush tip was bent and the magnitude of the load read on the dial of the gauge was recorded, which was approximately 80 gf. This reading was considered as the maximum load to be applied in one main group (80). In the other main group, a load of 40 gf was applied (40). During the rubbing process, the tip of the brush was at a right angle to the dentin surface. Maximum force indicator of the gauge was set to $40 \mathrm{gf}$ or $80 \mathrm{gf}$, with respect to the group tested to ensure that the applied force did not exceed the limit values.

After the adhesives were applied as described above, a mild oil-free air stream was blown for $5 \mathrm{~s}$ followed by light curing for $10 \mathrm{~s}$ with a curing unit with an output intensity of $900 \mathrm{~mW} / \mathrm{cm}^{2}$ (Elipar Freelight II, 3M ESPE) according to manufacturers' instructions. Resin composite (Clearfil Majesty Esthetic A2, Kuraray Noritake Dental) build-ups were constructed in double 2 $\mathrm{mm}$ increments, with each increment being light-cured for $20 \mathrm{~s}$. All adhesive and restorative procedures were performed by a single operator. In each group, half of the specimens were stored in distilled water at $37^{\circ} \mathrm{C}$ for $24 \mathrm{~h}$ (BL). The other half of the specimens of each group were subjected to thermal aging (TA) in distilled water for 10,000 cycles $\left(5-55^{\circ} \mathrm{C}\right.$, with a dwell time of $60 \mathrm{~s}$ and transfer time of $5 \mathrm{~s}$ ). Six teeth were used per experimental group $(n=6)$.

\section{$\mu T B S$ test}

After water storage and aging, specimens were longitudinally sectioned in both the " $x$ " and " $y$ " directions across the bonded interface with a diamond saw (IsoMet Wafering Blades -15LC, Buehler) in a sectioning machine (IsoMet Low Speed Saw, Buehler) under water cooling at $300 \mathrm{rpm}$ to obtain bonded sticks with a crosssectional area of approximately $1 \mathrm{~mm}^{2}$. Sticks were kept moist until testing. Each stick was attached to a device (Bisco Microtensile Tester, Bisco, Schaumburg, IL, USA) with cyanoacrylate adhesive (Zapit Introductory Assortment, Dental Ventures of America, Corona, CA, USA) and was subjected to a tensile force at a crosshead speed of $0.5 \mathrm{~mm} / \mathrm{min}$ until failure. Bond strength [MPa] was calculated by dividing the load at failure $[\mathrm{N}]$ by the bonded surface area $\left[\mathrm{mm}^{2}\right]$. The failure modes were evaluated at 50× magnification (SV 6 , Zeiss) and classified as cohesive (failure exclusively within dentin or composite), adhesive (failure at the resin/dentin interface) or mixed (failure at resin/dentin interface that included small portions of the neighboring substrates).

\section{Statistical analysis}

Specimens which exhibited pre-testing or cohesive failures were excluded from statistical analysis ${ }^{17,18)}$. Before submitting the data to the appropriate statistical analysis, D'agostino Pearson test was performed to assess whether the data followed a normal distribution. After observing the data were normally distributed, two-way analysis of variance and Tukey's test was used $(\alpha=0.05)$. A commercially available software was used for all statistical analyses (Prism 6.0, GraphPad Software, La Jolla, CA, USA).

\section{RESULTS}

The interaction adhesive/rubbing load was statistically significant $(p<0.001) . \mu$ TBS and the respective standard deviations for all groups are shown in Table 3. CL adhesive performed better when applied with a vigorous rubbing action when compared with SB adhesive at both baseline and TA evaluations. Baseline bond strength values for CL adhesive were improved by vigorous rubbing (40 and $80 \mathrm{gf}$ ) when compared with no rubbing $(p<0.05)$. However, increasing the load from 40 gf to 80 gf did not further improve the bond strength values of CL adhesive $(p>0.05)$. Rubbing force did not significantly improve the bond strength values for SB adhesive when compared with no rubbing, regardless of aging $(p>0.05)$. Bond strength values for all experimental groups were not influenced by aging $(p>0.05)$. Frequency of failure modes for all groups is shown in Table 4. Majority of the failure modes were adhesive, regardless of aging.

Table 3 Microtensile bond strength values and their standard deviations [MPa]*

\begin{tabular}{llccc}
\hline & & & \multicolumn{2}{c}{ Rubbing action } \\
\cline { 3 - 5 } & & NR & 40 & 80 \\
\hline \multirow{2}{*}{ Baseline } & SB & $25.15 \pm 5.05 \mathrm{Aa}$ & $28.30 \pm 6.88 \mathrm{Aa}$ & $25.30 \pm 5.57 \mathrm{Aa}$ \\
& CL & $21.23 \pm 5.81 \mathrm{Aa}$ & $36.36 \pm 6.42 \mathrm{Bb}$ & $32.33 \pm 7.65 \mathrm{Bb}$ \\
Thermal aging & & & & $25.83 \pm 6.24 \mathrm{Aa}$ \\
& SB-TA & $26.05 \pm 4.16 \mathrm{Aa}$ & $28.82 \pm 6.47 \mathrm{Aa}$ & $33.92 \pm 6.99 \mathrm{Bb}$
\end{tabular}

*A total of 504 bonded dentin-composite sticks were analyzed.

Uppercase letters compare means in each row.

Lowercase letters compare means in each column.

Means sharing letter are not significantly different $(p>0.05)$. 
Table 4 Percentage (\%) of the failure modes of the fractured specimens

\begin{tabular}{|c|c|c|c|}
\hline \multirow{2}{*}{\multicolumn{2}{|c|}{ Experimental group }} & \multicolumn{2}{|c|}{ Failure mode } \\
\hline & & Adhesive & Mixed \\
\hline \multirow{6}{*}{ Baseline } & SB-NR & 89.5 & 10.5 \\
\hline & SB-40 & 87.7 & 12.3 \\
\hline & SB-80 & 93.0 & 7.0 \\
\hline & CL-NR & 96.8 & 3.2 \\
\hline & CL-40 & 90.4 & 9.6 \\
\hline & CL-80 & 94.2 & 5.8 \\
\hline \multirow{6}{*}{ Thermal aging } & SB-NR-TA & 97.5 & 2.5 \\
\hline & SB-40-TA & 95.4 & 4.6 \\
\hline & SB-80-TA & 96.0 & 4.0 \\
\hline & CL-NR-TA & 100.0 & 0.0 \\
\hline & CL-40-TA & 97.3 & 2.7 \\
\hline & CL-80-TA & 97.4 & 2.6 \\
\hline
\end{tabular}

\section{DISCUSSION}

When a manual force is applied during rubbing of the adhesives onto dentin surface, dentin acts like a sponge and the dentin collagen network is compressed. Compressed collagen expands as the pressure is relieved and the infiltration of the adhesive into collagen network may be improved ${ }^{13)}$. Rubbing action also improves the evaporation of the solvent of the adhesive systems ${ }^{6}$. In this study, rubbing action improved the bond strength values of CL regardless of aging. However, SB was not affected by rubbing action. Rubbing CL with a load of 80 gf did not further improve bond strength when compared to $40 \mathrm{gf}$. Therefore, the null hypothesis was partially rejected.

A previous study ${ }^{11)}$ mentioned the magnitude of rubbing force and determined the load to be applied by training the operator using an analytical balance; and applied $4 \pm 1$ and $34.5 \pm 6.9$ g of load for "slight rubbing" and "vigorous rubbing" action. The majority of studies investigating the effect of rubbing force refer to that study ${ }^{7-9,13,16)}$. Other studies did not give any details about the determination of the applied force ${ }^{10,12,14,19)}$. In this study, to standardize the application of rubbing force to its highest, a more consistent approach was used. A rigid microbrush was attached to a force gauge and rubbing force was visually inspected throughout the adhesive procedures. Therefore, intra-operator variability was minimized. A load of $80 \mathrm{gf}$ was chosen as a limit to be applied, since the microbrush started to bend notably beyond 80 gf. In all rubbing groups, the applied force ranged between the maximum load and $5 \mathrm{~g}$ lower than the maximum.

Universal adhesives, CL and SB, in this study contain 10-methacryloyloxydecyl dihydrogen phosphate (MDP) monomer. This monomer was originally synthesized and patented by one manufacturer (Kuraray Noritake Dental). Recently, this patent had expired and other manufacturers began incorporating this or a similar monomer into their products. One of the advantages of MDP over other functional self-etching monomers is its ability to form a hydrolytically stable ionic bond with the calcium in hydroxyapatite ${ }^{20,21)}$. SB universal adhesive additionally contains Vitrebond copolymer, which is a methacrylate modified polyalkenoic acid copolymer. It is a high-molecular-weight structure, which may compete with MDP for bonding to calcium of hydroxyapatite ${ }^{22)}$ and may also prevent monomer approximation during polymerization $^{23)}$. This may partially explain the lower bond strength values of SB when compared with CL in 40 and 80 rubbing force groups, regardless of aging. However, there were no differences between bond strengths of CL and SB applied without rubbing. Rubbing action might have promoted deeper infiltration of MDP into the collagen network, but possibly not of the Vitrebond copolymer due to its high molecular weight ${ }^{23)}$, resulting in lower performance of SB compared to CL. Additionally, manufacturers of both CL and SB recommends an active application of the adhesives; therefore, their performance may vary when applied without rubbing. Future studies are needed to test this hypothesis.

Dentin bond strength tests commonly applied in dental material science cause pre-testing, cohesive, adhesive or mixed failures. Many investigators include cohesive and pre-test failures in their statistical analyses. A literature review suggests that cohesive failures should not be included in the statistical analysis ${ }^{17)}$, since they test physical properties of dentin or resin composite rather than the adhesive interface ${ }^{24)}$. Additionally, pre-testing failures and mixed failures involving large portions of dentin or resin should also be discarded ${ }^{17}$. In this study, failure interfaces were evaluated under high magnification and only adhesive and mixed failures with small portions of neighboring substrates were included in the statistical analysis to 
minimize scatter of bond strength data. Failure analysis revealed a predominant adhesive failure after TA. This could be due to aging of the adhesive layer and consequently yielding more adhesive failures when compared to mode of baseline failures.

Thermal cycling is a common method to simulate intraoral aging and stresses applied to the bonding interface in conjunction with bond strength tests ${ }^{25}$. It was suggested that 10,000 cycles of in vitro TA represents a year of clinical service ${ }^{25}$. In this study, 10,000 cycles were applied, but bond strength values were not negatively affected for both CL and SB adhesives $(p>0.05)$. The hydrophobic nature of MDP that protects hybrid layers from hydrolytic degradation ${ }^{22)}$ may explain this result. In accordance with our study, no difference between bond strength values for SB adhesive at baseline and after 5,000 TA cycles was found by Wagner et al. ${ }^{18)}$.

Acidity of the adhesive play an important role regarding their etching potential of the dental substrates. A mild $(\mathrm{pH} \approx 2)$ and ultra-mild $(\mathrm{pH} \geq 2.5)$ adhesives $^{26)}$ are less aggressive on dentin ${ }^{27}$. A mild etching partially removes the hybrid layer and leaves notable amount of hydroxyapatite around collagens thus gives an opportunity for functional monomers to form chemical bond ${ }^{21)}$. Ultra-mild etching does not completely remove the collagen, only superficial collagen is exposed ${ }^{28}$. The $\mathrm{pH}$ of the adhesives, CL and $\mathrm{SB}$, used in this study were 2.3 and 2.7 respectively. The higher $\mathrm{pH}$ of SB might partly explain the lower bond strength values when compare to CL. However, uniformity rather than thickness of hybrid layer is more important ${ }^{26)}$ and therefore deductions should be made carefully.

Three studies investigated the effect of rubbing force on bond strength of one-step SE adhesives to dentin ${ }^{7-9)}$, demonstrating that rubbing of the adhesive improves the bond strength to dentin after $24 \mathrm{~h}$ as compared to application without rubbing. Universal adhesives (CL, SB) tested in this study were applied in SE mode. Rubbing action improved dentin bond strengths only with the CL adhesive. Although universal adhesives are basically one-step SE adhesives, they have different chemical compositions to be able to bond to different substrates and, therefore, may perform different than one-step SE adhesives. Since this is the first study to investigate the effect of rubbing force magnitude on bond strength of universal adhesives applied in SE mode, our results cannot be directly compared to previous studies performed with one-step SE adhesives. In addition, test methods, sample preparation, and statistical analyses impact results and cause the variability of bond strength values between different studies ${ }^{17}$. Further studies including more and different materials are necessary to validate the findings of current study.

\section{CONCLUSION}

Rubbing improves bonding performance of a particular universal adhesive to dentin when applied in self-etch mode, but is ineffective to another universal adhesive.
Rubbing force magnitude and simulated aging had no significant effect on bond strength values.

\section{CONFLICTS OF INTEREST}

The authors deny any conflicts of interest.

\section{REFERENCES}

1) Pashley DH, Tay FR, Breschi L, Tjaderhane L, Carvalho RM, Carrilho M, Tezvergil-Mutluay A. State of the art etch-andrinse adhesives. Dent Mater 2011; 27: 1-16.

2) Van Meerbeek B, Yoshihara K, Yoshida Y, Mine A, De Munck J, Van Landuyt KL. State of the art of self-etch adhesives. Dent Mater 2011; 27: 17-28.

3) Rosa WL, Piva E, Silva AF. Bond strength of universal adhesives: A systematic review and meta-analysis. J Dent 2015; 43: 765-776.

4) Alex G. Universal adhesives: the next evolution in adhesive dentistry? Compend Contin Educ Dent 2015; 36: 15-26- quiz 8-40.

5) De Munck J, Van Landuyt K, Peumans M, Poitevin A, Lambrechts P, Braem M, Van Meerbeek B. A critical review of the durability of adhesion to tooth tissue: methods and results. J Dent Res 2005; 84: 118-132.

6) Reis A, Carrilho M, Breschi L, Loguercio AD. Overview of clinical alternatives to minimize the degradation of the resindentin bonds. Oper Dent 2013; 38: E1-E25.

7) Loguercio AD, Stanislawczuk R, Mena-Serrano A, Reis A. Effect of 3-year water storage on the performance of one-step self-etch adhesives applied actively on dentine. J Dent 2011; 39: $578-587$

8) do Amaral RC, Stanislawczuk R, Zander-Grande C, Michel $\mathrm{MD}$, Reis A, Loguercio AD. Active application improves the bonding performance of self-etch adhesives to dentin. J Dent 2009; 37: 82-90

9) do Amaral RC, Stanislawczuk R, Zander-Grande C, Gagler D, Reis A, Loguercio AD. Bond strength and quality of the hybrid layer of one-step self-etch adhesives applied with agitation on dentin. Oper Dent 2010; 35: 211-219.

10) Miyazaki M, Platt JA, Onose H, Moore BK. Influence of dentin primer application methods on dentin bond strength. Oper Dent 1996; 21: 167-172.

11) Dal-Bianco K, Pellizzaro A, Patzlaft R, de Oliveira Bauer JR, Loguercio AD, Reis A. Effects of moisture degree and rubbing action on the immediate resin-dentin bond strength. Dent Mater 2006; 22: 1150-1156.

12) Jacobsen T, Söderholm KJ. Effect of primer solvent, primer agitation, and dentin dryness on shear bond strength to dentin. Am J Dent 1998; 11: 225-228.

13) Reis A, Pellizzaro A, Dal-Bianco K, Gones OM, Patzlaff R, Loguercio AD. Impact of adhesive application to wet and dry dentin on long-term resin-dentin bond strengths. Oper Dent 2007; 32: 380-387.

14) Tewari S, Goel A. Effect of placement agitation and drying time on dentin shear bond strength: an in vivo study. Oper Dent 2009; 34: 524-530.

15) Chan KM, Tay FR, King NM, Imazato S, Pashley DH. Bonding of mild self-etching primers/adhesives to dentin with thick smear layers. Am J Dent 2003; 16: 340-346.

16) Loguercio AD, Raffo J, Bassani F, Balestrini H, Santo D, do Amaral RC, Reis A. 24-month clinical evaluation in noncarious cervical lesions of a two-step etch-and-rinse adhesive applied using a rubbing motion. Clin Oral Investig 2011; 15: 589-596.

17) Scherrer SS, Cesar PF, Swain MV. Direct comparison of the bond strength results of the different test methods: a critical literature review. Dent Mater 2010; 26: e78-93. 
18) Wagner A, Wendler M, Petschelt A, Belli R, Lohbauer U. Bonding performance of universal adhesives in different etching modes. J Dent 2014; 42: 800-807.

19) Velasquez LM, Sergent RS, Burgess JO, Mercante DE. Effect of placement agitation and placement time on the shear bond strength of 3 self-etching adhesives. Oper Dent 2006; 31: 426430.

20) Van Landuyt KL, Snauwaert J, De Munck J, Peumans M, Yoshida Y, Poitevin A, Coutinho E, Suzuki K, Lambrechts P, Van Meerbeek B. Systematic review of the chemical composition of contemporary dental adhesives. Biomaterials 2007; 28: 3757-3785.

21) Yoshida Y, Nagakane K, Fukuda R, Nakayama Y, Okazaki M, Shintani H, Inoue S, Tagawa Y, Suzuki K, De Munck J, Van Meerbeek B. Comparative study on adhesive performance of functional monomers. J Dent Res 2004; 83: 454-458.

22) Yoshida Y, Yoshihara K, Nagaoka N, Hayakawa S, Torii Y, Ogawa T, Osaka A, Meerbeek BV. Self-assembled Nanolayering at the Adhesive interface. J Dent Res 2012; 91: 376-
381.

23) Munoz MA, Luque I, Hass $V$, Reis A, Loguercio AD, Bombarda $\mathrm{NH}$. Immediate bonding properties of universal adhesives to dentine. J Dent 2013; 41: 404-411.

24) Van Noort R, Cardew GE, Howard IC, Noroozi S. The effect of local interfacial geometry on the measurement of the tensile bond strength to dentin. J Dent Res 1991; 70: 889-893.

25) Gale MS, Darvell BW. Thermal cycling procedures for laboratory testing of dental restorations. J Dent 1999; 27: 8999

26) Van Meerbeek B, Peumans M, Poitevin A, Mine A, Van Ende A, Neves A, De Munck J. Relationship between bond-strength tests and clinical outcomes. Dent Mater 2010; 26: e100-121.

27) Tay FR, Pashley DH. Aggressiveness of contemporary selfetching systems. I: Depth of penetration beyond dentin smear layers. Dent Mater 2001; 17: 296-308.

28) Koshiro K, Sidhu SK, Inoue S, Ikeda T, Sano H. New concept of resin-dentin interfacial adhesion: the nanointeraction zone. J Biomed Mater Res B Appl Biomater 2006; 77: 401-408. 